\title{
CROSS-SHORE VARIATIONS IN SEDIMENT STRENGTH AT A SANDY BEACH
}

\author{
Bridgit Reeve, Virginia Polytechnic Institute and State University, breeve@vt.edu \\ Nina Stark, Virginia Polytechnic Institute and State University, ninas@vt.edu \\ Peter Mewis, Technische Universität Darmstadt, mewis@wb.tu-darmstadt.de
}

\section{MOTIVATION}

The potential for erosion and accretion of coastal sediments is governed by local hydrodynamics and sediment characteristics. These factors are highly spatially and temporally variable and strongly interact in the surf zone. It is known that for any change in the wave load, the system quickly seeks and adopts a new state of equilibrium. It follows that the understanding of the interactions between hydrodynamics and sediment properties is crucial for beach engineering. Particularly, there seems to be a lack of knowledge regarding the role of geotechnical sediment properties. The research goal of this study is to characterize the cross-shore variation of sediment strength across a sandy, erosive beach on the island of Sylt, Germany.

\section{METHODOLOGY}

To obtain an estimate of in situ sediment strengths, a freefall penetrometer (FFP) was deployed at 20 locations along the cross-shore profile of a sandy, microtidal beach with a high wave load on the western coast of Sylt during low tide. Sediment strength was determined from deceleration records and expressed as quasi-static bearing capacity (qsbc) (Stark et al., 2009). Sand samples were collected at 18 locations in the cross-shore profile for sieve analyses, as well as fully saturated direct shear tests at low relative density. The samples were taken to a depth of $10 \mathrm{~cm}$.

\section{RESULTS}

Figure 1 shows variations in qsbc determined using the FFP from the swash zone, through the intertidal zone, and into the subaerial zone. The cross-shore distance of zero corresponds to the water level during the time of the study. Variations in strength reflect three main trends. The strongest sediments were found in the uppermost swash zone and decreased toward the intertidal zone, exhibiting qsbc $\approx 50 \mathrm{kPa}$ with some variations. The weakest sediments were found in the subaerial zone, suggesting the significance of moisture content. Negative pore pressures due to capillary rise in partially saturated sediments cause intergranular stress and frictional resistance between sediment grains (Holtz et al., 2011), which may contribute to the higher strengths observed in the intertidal and swash zones. Sediment strength increases significantly entering the swash

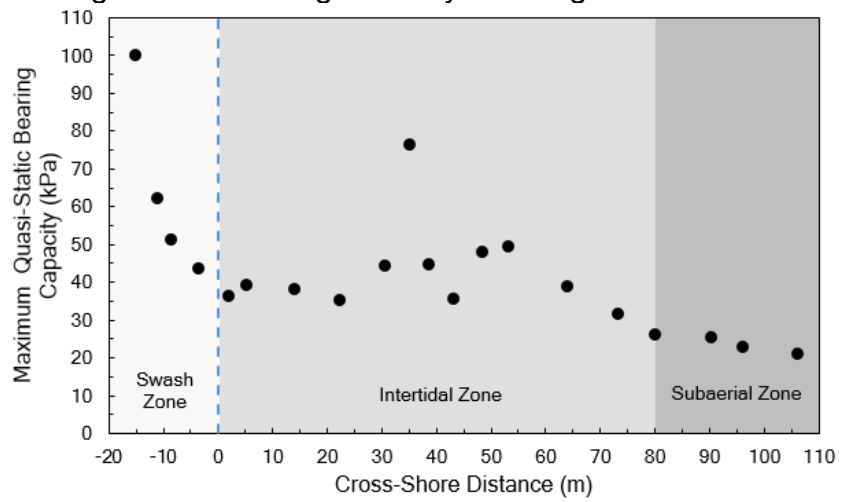

Figure 1 - Maximum qsbc in the cross-shore profile

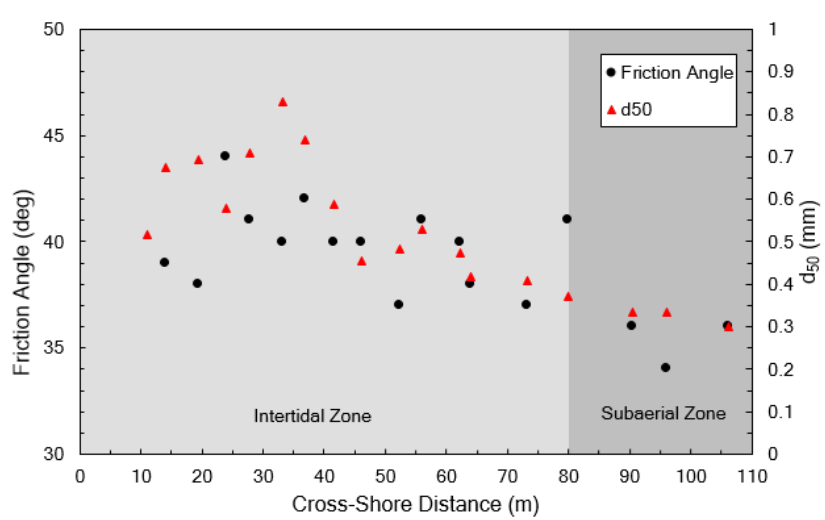

Figure 2 - Variation friction angle and median grain size in cross-shore profile

zone, corresponding to the location of maximum water inundation prior to the experiment. The swash may be eroding finer and looser deposits, leaving dense, compacted sediment in this zone. Laboratory characterization of sediment samples is shown in figure 2. In general, friction angle and median grain size tend to decrease moving onshore. Based on USCS definitions, the sediment in the intertidal zone is a mix of fine to medium sand, transitioning to almost entirely fine sand in the subaerial zone. Gradation characteristics and strengths obtained from direct shear tests suggest that sediment strength tends to decrease in the onshore direction. Unfortunately, no sediment samples were recovered in the swash zone, but samples approaching the swash zone appear to suggest a sediment coarsening.

\section{DISCUSSION AND CONCLUSIONS}

Variations in sediment strength were observed along a cross-shore transect stretching from the swash zone, across a partially saturated intertidal zone, and into the subaerial zone. As expected, sediment saturation and moisture content impact and contribute to sediment strength (Briaud, 2013). Sediments in the subaerial zone were found to have the lowest strengths. The significant increase in strength recorded in the swash zone may be associated to in situ densification and sediment sorting by the swash, as well as an increase in moisture content. The results suggest rapid spatial and temporal variations in sediment strength which likely impact sediment erodibility. Future erosion prediction in the context of beach nourishment may be improved by incorporating such behavior, but more investigations are needed.

\section{REFERENCES}

Briaud (2013): Geotechnical engineering: unsaturated and saturated soils, John Wiley and Sons, Hoboken, USA. Holtz, Kovacs, Sheahan (2011): An Introduction to Geotechnical Engineering, Pearson Education Inc, Upper Saddle River, NJ, pp. 219-226.

Stark, Kopf, Hanff, Stegmann, Wilkens, (2009): Geotechnical investigations of sandy seafloors using dynamic penetrometers, in OCEANS 2009, MTS/IEEE Biloxi-Marine Technology for Our Future: Global and Local Challenges, IEEE, pp. 1-10. 